\title{
Rapid review (partial rescreening) of cervical cytology. Four years experience and quality assurance implications
}

Cytology Department, Conquest Hospital, St Leonards-on-Sea, East Sussex TN37 7RD

Correspondence to: Mr C A Faraker.

\section{A Faraker, M E Boxer}

\begin{abstract}
Aims-To determine the sensitivity of the partial rescreening method of rapid review for internal quality control of cervical cytology; to determine which staff members are most suited to undertake it; and to investigate the cell patterns of false negative smears previously detected by the method.
\end{abstract}

Methods-As a prospective study 9517 cervical smears were partially screened by four cytotechnologists using the 'step' method prior to conventional screening and the results compared with the final report. As a retrospective study 62 false negative smears that had been identified by the method over four years were reviewed.

Results-A detection rate for dyskaryosis of $86 \%$ (range $82-91 \%$ ) was achieved. Sixteen abnormal smears were missed on conventional screening that had been detected by prescreening. Review of the 62 false negatives revealed three patterns: (1) scanty abnormal cells; (2) abundant dyskaryotic cells presenting as "microbiopsies"; and (3) abundant, readily recognisable abnormal cells.

Conclusions-Partial rescreening enables the detection of errors due to both fatigue and misinterpretation. In this laboratory the method has, together with targeted full rescreening, reduced the false negative report rate from $5.0 \%$ to $0.4 \%$. For laboratories using a rapid review method to reduce false negative reports, a prescreening trial is recommended in order (1) to select the most effective review method and the staff most suited to undertake it; and (2) to determine the laboratory's sensitivity with the method, as this is required for accurate estimation of the false negative rate.

(F Clin Pathol 1996;49:587-591)

Keywords: partial rescreening, rapid review, cervical screening, internal quality control.

According to Koss one of the tragedies of cervical cytology is the high incidence of false negative smear reports issued by cytology laboratories. ${ }^{1}$ In a British study, $65 \%$ of cervical smears reported as negative, taken from women who later developed invasive disease, were found to contain dyskaryotic cells on review. ${ }^{2}$ The screening false negative rate for intraepithelial neoplasia is believed to be less than that for invasive carcinoma, but in some laboratories it may be as high as $20 \% .^{3-5}$ In the United States there has been much media attention devoted to screening errors ${ }^{6}{ }^{7}$ and in Britain occasional reports appear in the press.

Traditional methods of internal quality control, such as targeted rescreening of previously abnormal and symptomatic cases and 10\% random rescreening of negative smears, can only make a limited contribution to reducing the number of false negative reports. This is because only a small proportion of negative smears are rescreened. Recently, partial rescreening $^{89}$ and rapid screening ${ }^{10}{ }^{11}$ have been proposed as an improved alternative to $10 \%$ random rescreening as a method of internal quality control. The principle of partial rescreening, as proposed by one of us, is that all negative and inadequate smears are subjected to a quick review after conventional screening but prior to issue of the report. Partial rescreening and rapid screening are now known collectively by the umbrella term rapid review and are recommended to NHS laboratories by the Scottish Office Working Party on Internal Quality Control for Cervical Cytology Laboratories ${ }^{12}$ and a working party set up by the Royal College of Pathologists, the British Society for Clinical Cytology and the NHS Cervical Screening Programme. ${ }^{13}$

As this procedure is adopted it is important that each laboratory determines which method is to be used and which of its staff members are best qualified to undertake it, in order to maximise the portion of false negatives that are detected. The aim of this study was to investigate prospectively the performance of four cytotechnologists in carrying out partial rescreening and examine the factors that may influence ability with the method. In addition, we examined retrospectively 62 of the false negative smears that had been detected by rapid review between 1991 and 1994 to determine whether there were particular smear patterns that were habitually missed on conventional screening.

\section{Methods}

All cervical smears submitted to the laboratory were partially screened before conventional screening (which we call rapid preview). Each cytotechnologist partially screened the entire workload until each had encountered around 100 abnormal smears. The number of slides prescreened each day by each participant rarely 
Table 1 Detection rates for cytological abnormalities by rapid preview

\begin{tabular}{|c|c|c|c|c|c|c|c|c|c|c|}
\hline \multirow[b]{2}{*}{ Technologist } & \multirow{2}{*}{$\begin{array}{l}\text { Screening } \\
\text { experience } \\
\times 1000 \\
\text { smears }\end{array}$} & \multirow{2}{*}{$\begin{array}{l}\text { Screening } \\
\text { FN rate } \\
\text { as \% of } \\
\text { abnormals }\end{array}$} & \multirow[b]{2}{*}{$\begin{array}{l}\text { Total slides } \\
\text { prescreened }\end{array}$} & \multicolumn{4}{|c|}{ Grade of dyskaryosis detected by rapid preview } & \multirow{2}{*}{$\begin{array}{l}\text { Percentage } \\
\text { abnormals } \\
\text { detected }\end{array}$} & \multirow{2}{*}{$\begin{array}{l}\text { Percentage } \\
\text { dyskaryosis } \\
\text { detected }\end{array}$} & \multirow{2}{*}{$\begin{array}{l}\text { False } \\
\text { negative } \\
\text { detected }\end{array}$} \\
\hline & & & & Borderline & Mild & Moderate & Severe & & & \\
\hline A & 100 & 1.52 & 2234 & $\begin{array}{l}22 / 29 \\
(76 \%)\end{array}$ & $\begin{array}{l}23 / 26 \\
(88 \%)\end{array}$ & $\begin{array}{l}12 / 13 \\
(92 \%)\end{array}$ & $\begin{array}{l}29 / 31 \\
(93 \%)\end{array}$ & 87 & 91 & 10 \\
\hline B & 10 & 2.33 & 2691 & $\begin{array}{l}14 / 30 \\
(47 \%)\end{array}$ & $\begin{array}{l}22 / 27 \\
(81 \%)\end{array}$ & $\begin{array}{l}15 / 18 \\
(83 \%)\end{array}$ & $\begin{array}{l}22 / 27 \\
(81 \%)\end{array}$ & 72 & 82 & 2 \\
\hline $\mathrm{C}$ & 15 & 5.98 & 2567 & $\begin{array}{l}19 / 28 \\
(68 \%)\end{array}$ & $\begin{array}{l}24 / 28 \\
(86 \%)\end{array}$ & $\begin{array}{l}5 / 6 \\
(83 \%)\end{array}$ & $\begin{array}{l}32 / 39 \\
(82 \%)\end{array}$ & 79 & 84 & 0 \\
\hline $\mathrm{D}$ & 85 & NK & 2025 & $\begin{array}{l}21 / 27 \\
(78 \%)\end{array}$ & $\begin{array}{l}21 / 26 \\
(81 \%)\end{array}$ & $\begin{array}{l}21 / 22 \\
(95 \%)\end{array}$ & $\begin{array}{l}24 / 27 \\
(89 \%)\end{array}$ & 85 & 88 & 4 \\
\hline Total & & & 9517 & $\begin{array}{l}76 / 114 \\
(67 \%)\end{array}$ & $\begin{array}{l}90 / 107 \\
(84 \%)\end{array}$ & $\begin{array}{l}53 / 59 \\
(90 \%)\end{array}$ & $\begin{array}{l}107 / 124 \\
(86 \%)\end{array}$ & $\begin{array}{l}326 / 404 \\
(81 \%)\end{array}$ & $\begin{array}{l}250 / 290 \\
(86 \%)\end{array}$ & 16 \\
\hline
\end{tabular}

Note: severe dyskaryosis includes two cases of adenocarcinoma.

$\mathrm{NK}=$ not known (new staff member); $\mathrm{FN}=$ false negative.

exceeded 60. Each slide was assessed for cytological abnormalities and adequacy, and the results recorded on worksheets which were removed prior to conventional screening. The pattern of prescreening used was step screening plus one length, as described previously. ${ }^{8}$ Using the $\times 10$ objective and a $22 \times 40 \mathrm{~mm}$ coverslip, and with the microscope stage being moved at approximately normal screening speed, the procedure took 30 to 45 seconds. The size of each step in the diagonal part of the pattern was about one microscope field by two. By this method, about $20 \%$ of the area under the coverslip is examined (fig 1). If the cellular material was concentrated on one half of the slide, the fields examined were modified appropriately. The results of partial screening were compared with those of conventional screening; if there was any discrepancy between the two, the slides were reviewed and a final opinion given.

From 1991 to 1994,63 cervical smears that had been originally reported as negative on conventional screening, were found to contain abnormal cells on subsequent rapid review. Sixty two of these were reviewed with the following features noted. The number of abnormal cells were counted, accurately for the first 30 and then to the nearest 10 up to 100 . The number of fields in which the abnormal cells were found was also recorded. If the cells appeared in loose aggregates of more than 20 or as cohesive "microbiopsies", or were obscured by-for example, polymorphs, or represented pale dyskaryosis, this was noted.

Throughout this paper 'abnormal smear' is defined as one showing borderline change or any grade of dyskaryosis, and false negative refers to false abnormal.

The calculation of the screening false negative rate as a percentage of all abnormals, as shown in table 1 , was carried out as follows.

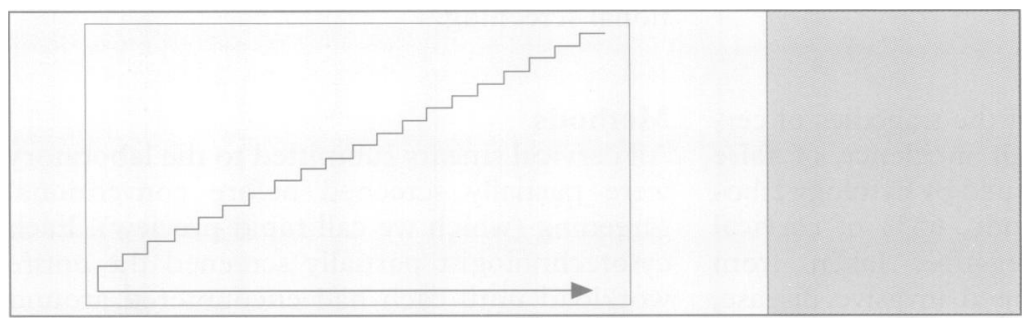

Figure 1 Screening pattern used in rapid review. Each step is approximately one field by two.
Over a four year period, the total number of $\vec{\circ}$ smears screened and the total number of abnormals as detected by a combination of $\vec{\omega}$ routine screening, rapid review (RR) and targeted full rescreening (TFR) is known from? computer records. Abnormal smears represent $\vec{c}$ $4.5 \%$ of the total. For the same period, the number of smears screened by each cytotech- o nologist is known from worksheets. For 0 screener A-for example, this was 17 509. This figure multiplied by the abnormal rate of $4.5 \%$ gives the number of abnormals screener $A ₹$ would be expected to encounter-that is, $788 \vec{\bullet}$ abnormals. The number of abnormal smears missed by screener $A$ and detected by $R R=80$ and by $T F R=4$. Therefore the number of false negatives per 100 abnormals for screener $A$ is $12 / 788 \times 100=1.52$.

\section{Results}

In total 9517 cervical and vault smears were prescreened by the four cytotechnologists, with each examining an average of 2380 . The detection rate of abnormal smears for each indi-용 vidual is shown in table 1 . There were 404 훔 abnormal smears (that is, showing borderline abnormality or dyskaryosis), of which $326 \%$ $(81 \%)$ were detected on prescreening. The detection rate for the cytotechnologists ranged 음 from 72 to $87 \%$. If dyskaryosis alone is consid- $\rightarrow$ ered, 290 of the 404 abnormal smears contained dyskaryotic cells and of these $250 \mathrm{~N}$ $(86 \%)$ were identified with a range for screen- $N$ ers of 82 to $91 \%$. There were 16 abnormal N smears found on prescreening that were missed ${ }_{\sigma}^{\omega}$ on subsequent conventional screening. The percentage of normal smears that were overcalled-that is, suspected of being abnor- $\stackrel{0}{+}$ mal, on prescreening ranged from 1.2 to $1.9 \%$ (average 1.6\%).

There were 599 smears that were considered $\stackrel{\mathbb{D}}{\stackrel{D}{\mathbb{D}}}$ inadequate (for any reason) on conventional $\stackrel{\mathbb{Q}}{\stackrel{\mathbb{Q}}{2}}$ screening and of these $379(63 \%)$ were correctly identified by prescreening (range for $\Omega$ screeners $37-73 \%$ ). Of those inadequate due to lack of transformation zone material, $66 \%$ (range 39-77\%) were detected. Two per cent of adequate smears were wrongly called inadequate by prescreening and in $0.6 \%$ the adequacy was wrongly judged on conventional screening (table 2).

For ease of presentation, the 62 false negative smears previously detected by rapid 
Table 2 Detection of inadequate smears by rapid preview

\begin{tabular}{|c|c|c|c|c|}
\hline \multirow[b]{2}{*}{ Technologist } & \multicolumn{2}{|c|}{$\begin{array}{l}\text { Smear inadequate } \\
\text { due to: }\end{array}$} & \multirow{2}{*}{$\begin{array}{l}\text { Overcalled as } \\
\text { inadequate by } \\
\text { rapid preview }\end{array}$} & \multirow{2}{*}{$\begin{array}{l}\text { Adequacy } \\
\text { corrected } \\
\text { by rapid } \\
\text { preview }\end{array}$} \\
\hline & $\begin{array}{l}\text { Absent } \\
T Z\end{array}$ & $\begin{array}{l}\text { Other } \\
\text { cause }\end{array}$ & & \\
\hline A & $\begin{array}{l}55 / 76 \\
(72 \%)\end{array}$ & $\begin{array}{l}27 / 40 \\
(67 \%)\end{array}$ & $\begin{array}{l}34 / 2118 \\
(1.6 \%)\end{array}$ & 21 \\
\hline B & $\begin{array}{l}36 / 93 \\
(39 \%)\end{array}$ & $\begin{array}{l}16 / 47 \\
(34 \%)\end{array}$ & $\begin{array}{l}34 / 2551 \\
(1.3 \%)\end{array}$ & 4 \\
\hline C & $\begin{array}{l}134 / 177 \\
(77 \%)\end{array}$ & $\begin{array}{l}35 / 55 \\
(64 \%)\end{array}$ & $\begin{array}{l}73 / 2338 \\
(3.1 \%)\end{array}$ & 10 \\
\hline D & $\begin{array}{l}65 / 92 \\
(71 \%)\end{array}$ & $\begin{array}{l}11 / 19 \\
(58 \%)\end{array}$ & $\begin{array}{l}39 / 1914 \\
(2.0 \%)\end{array}$ & 17 \\
\hline Total & $\begin{array}{l}290 / 438 \\
(66 \%)\end{array}$ & $\begin{array}{l}89 / 161 \\
(55 \%)\end{array}$ & $\begin{array}{l}180 / 8921 \\
(2.0 \%)\end{array}$ & $\begin{array}{l}52 / 8921 \\
(0.6 \%)\end{array}$ \\
\hline
\end{tabular}

$\mathrm{TZ}=$ transformation zone.

review over a four year period are classified as low grade abnormality (borderline change, human papilloma virus infection and mild dyskaryosis ) and high grade abnormality (severe dyskaryosis and carcinoma). There were no cases of moderate dyskaryosis. Considering smears showing low grade abnormality, 34 $(68 \%)$ of 50 had 20 or less abnormal cells per slide (fig 2). In three cases the cells were partially obscured and a further three represented pale dyskaryosis. Loose aggregates of more than 20 cells were observed on 11 smears. Of 12 high grade smears, seven $(58 \%)$ contained more than 100 cells, which in five cases numbered several hundreds, with the abnormal cells presenting as cohesive "microbiopsies". None of the high grade abnormality smears were regarded as pale dyskaryosis nor were the cells obscured. For both categories of smear the number of fields in which the abnormal cells appeared approximately corresponded with the number of abnormal cells (fig 3). Abnormal cells occupied five or less fields in $39(78 \%)$ of 50 cases with low grade

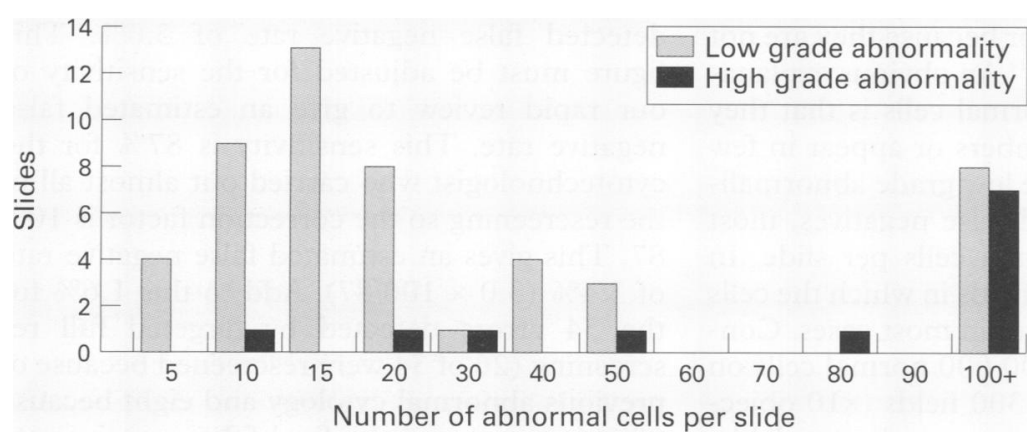

Figure 2 Cellularity of 62 reviewed false negative smears detected by rapid review.

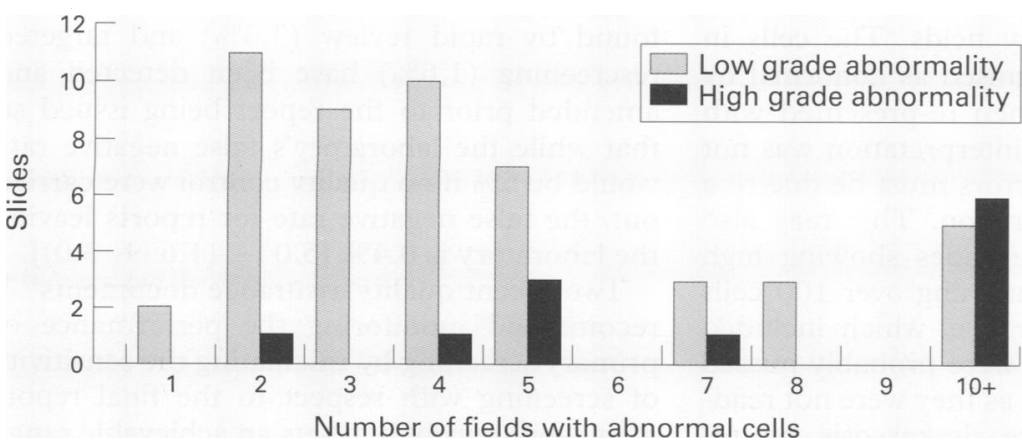

Figure 3 Number of fields in which abnormal cells appeared in 62 reviewed false negative smears detected by rapid review. abnormality, and more than 10 fields in six $(50 \%)$ of 12 high grade smears.

\section{Discussion}

DETECTION OF ABNORMAL SMEARS BY PRESCREENING (TABLE 1)

The screening false negative rate does not seem to correlate with success at rapid review. The false negative rates given in table 1 (column 3 ) for members of the laboratory represent all the false negatives detected by rapid review and targeted rescreening over a four year period (see Methods). One would perhaps expect a screener with a low false negative rate to achieve a high detection rate at rapid review. While this is true of cytotechnologist $\mathrm{A}$, two others (B and $\mathrm{C}$ ) performed equally yet have a notably different false negative rate $(2.33 \%$ and $5.98 \%$ ).

Of 16 abnormal smears missed on conventional screening, 10 were detected by screener A on prescreening. Although this may suggest that screener $A$ is more adroit at picking up errors it must be viewed in the context of who was carrying out the conventional screening during each participant's session. During screener A's trial, $70 \%$ of the screening was carried out by two screeners with false negative rates of $5.98 \%$ and $7.7 \%$, both of which rose to over $10 \%$ during this period. When screeners $B$ and $C$ (two and no false negatives detected) were carrying out the prescreening, the cytotechnologist with the $7.7 \%$ false negative rate was no longer screening and the bulk of the work was undertaken by a screener whose false negative rate is $1.52 \%$.

Previous experience with the partial rescreening method of rapid review did not seem to influence success with the method. Screener A was the only participant with any significant experience with the method, having viewed over 50000 slides, yet his detection rate was matched by $\mathrm{D}$ who has used the method on less than 1000. Screener B had experience of only a few 100 smears and $C$ had none; both performed equally well. One might expect performance to improve as one gets used to the technique; however, detection rates throughout each participant's trial varied little, suggesting that there is no learning curve involved (fig 4). This is not surprising as the only learning required is to master the technique of stepping, and this was achieved quickly by all participants.

Of interest is the higher detection rate achieved for mild dyskaryosis in this study $(84 \%)$ compared with that quoted in the Scottish Office document ${ }^{12}$ (between 50 and $72 \%$ ). The reasons for this difference are not clear; however, their method of rapid review is not stated.

INADEQUATE SMEARS (TABLE 2)

Rapid review has a contribution to make in checking for adequacy as in this study $\mathbf{5 2}$ $(0.6 \%)$ reports were adjusted prior to issue in view of the prescreening findings. However, as lack of transformation zone material is no 


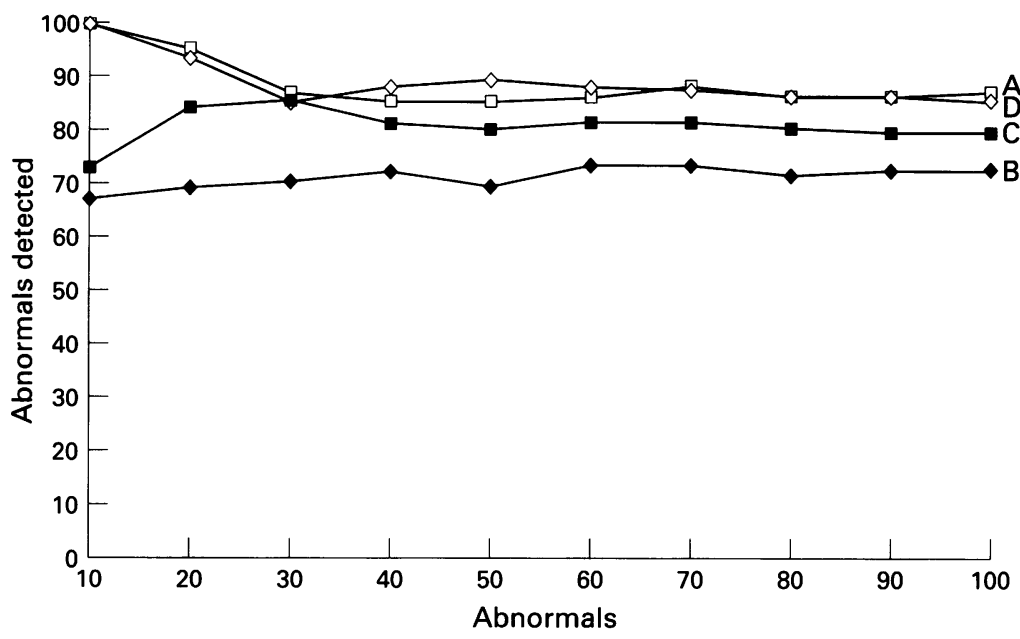

Figure 4 Learning curves for rapid preview (screeners $A, B, C$, and D). Detection rates changed little after 40 abnormals had been enountered.

longer necessarily considered evidence of inadequacy ${ }^{13}$ these results should be viewed in the light of this.

As an additional experiment during the course of this study, one of us determined how accurately a smear lacking indicators of probable transformation zone sampling could be identified with the naked eye. The characteristic appearance was of cellular material distributed in clumps and an absence of streaks and swirls of mucus. Of 1062 smears, 96 were considered in this category on microscopy and of these $70(73 \%)$ had been correctly identified macroscopically (there was a $2 \%$ overcall). This is a similar detection rate to partial screening and we find it a useful exercise to look for these features prior to screening.

\section{RETROSPECTIVE REVIEW OF FALSE NEGATIVE} SMEARS (FIGS 2 AND 3)

False negative cytology smears due to laboratory error may occur because the abnormal cells are either not seen or because they are not recognised as abnormal. ${ }^{14}$ An obvious explanation for not seeing abnormal cells is that they are present in small numbers or appear in few microscope fields. Of the low grade abnormalities among the reviewed false negatives, most had 20 or fewer abnormal cells per slide. In addition, the number of fields in which the cells appeared was five or fewer in most cases. Considering there may be 300000 normal cells on each smear and around 300 fields $(\times 10$ objective), these errors are perhaps understandable. At the other end of the spectrum were eight low grade abnormalities with over 100 cells per slide appearing in many fields. The cells in these were readily recognised as abnormal by the original screener when re-presented with the slide. Therefore, as interpretation was not the explanation, these errors must be due to a major lapse in concentration. This may also explain why two of the slides showing high grade abnormalities containing over 100 cells were missed. The other five, which included three adenocarcinomas, were probably missed due to misinterpretation as they were not readily recognised as severe dyskaryosis on representation. In these, the dyskaryotic cells were present in "microbiopsies" consistent with the fragments of severely dysplastic epithelium described by Robertson and Woodend, ${ }^{2}$ who found this presentation in 24 of 92 false negative smears from women who later developed cervical cancer. Of the remaining five high grade smears, two or three were prob- $\Omega$ ably missed due to scanty cellularity and the rest due to screening fatigue.

It is apparent that rapid review can be used to detect errors due to fatigue and those due to misinterpretation, the latter only if the cytolo- $\overrightarrow{\bar{c}}$ gist undertaking the procedure is familiar withall presentations of dyskaryosis. For this듬 reason, although participant $\mathrm{C}$ performed well in the study, we know from the results of rapid $\mathbb{\alpha}$ review over four years that this screener has difficulty recognising adenocarcinoma and

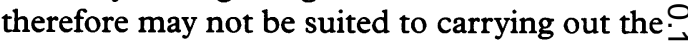
procedure as a quality control method.

It has been suggested that “...even the best ? laboratory will have difficulty in bettering a $5 \%$ 응 false negative rate" for primary screening. ${ }^{13}{ }^{15}$ 응 We consider, however, that this can be. improved for overall laboratory performance ${ }_{\infty}$ by the use of rapid review. There is not usually anything particularly 'difficult' about false ${ }^{3}$ negative smears, they are mostly missed for the $\vec{c}$ reasons outlined above. Robertson and Woodend $^{2}$ found that only around $10 \%$ of their $92 \vec{\circ}$ false negatives contained so few dyskaryotic cells that "...there seemed little prospect of." detection by normal screening methods". However, many of the false negatives reviewed in the present study contained very few abnormal cells, yet were detected by rapid review. We $\frac{\mathscr{\odot}}{\varnothing}$ have shown that use of rapid review enables the detection of up to $87 \%$ of abnormal smears and it would therefore be reasonable to suggest that it enables the detection of up to $87 \%$ of false negative smears. This laboratory has, in four years, detected 63 false negatives out of 2124 abnormal smears using rapid review, a윽 detected false negative rate of $3.0 \%$. This figure must be adjusted for the sensitivity of our rapid review to give an estimated false negative rate. This sensitivity is $87 \%$ for the윽 cytotechnologist who carried out almost all of the rescreening so the correction factor is $100 /$ ․․․ 87. This gives an estimated false negative rate $\mathrm{N}$ of $3.4 \%(3.0 \times 100 / 87)$. Add to this $1.6 \%$ for the 34 errors detected by targeted full re-N screening ( 26 of 34 were rescreened because of ${ }^{\omega}$ previous abnormal cytology and eight because of symptoms) and the final false negative rate for the laboratory becomes $5.0 \%$, exactly the suggested benchmark. However, the errors 0 found by rapid review (3.0\%) and targeted rescreening $(1.6 \%)$ have been detected and $\stackrel{\mathbb{\Phi}}{\stackrel{D}{\circ}}$ amended prior to the report being issued so $\stackrel{\mathbb{Q}}{\mathbb{Q}}$ that while the laboratory's false negative rate would be $5 \%$ if no quality control were carried 8 out, the false negative rate for reports leavingo the laboratory is $0.4 \%$ [5.0 - $(1.6+3.0)]$.

Two recent quality assurance documents ${ }^{12}{ }_{13}$ recommend monitoring the performance of primary screening by calculating the sensitivity of screening with respect to the final report after rapid review, and sets an achievable range of $85-95 \%$. This laboratory's sensitivities using this criteria are $97 \%(2124 /[2124+63] \times$ 
100) for all abnormalities and $98.6 \%$ (847/ $[847+12] \times 100)$ for moderate dyskaryosis or worse. These figures are misleadingly flattering as they do not include false negatives detected by targeted full rescreening nor do they take into account the correction factor for the sensitivity of rapid review. If we include these our final sensitivities come down to $95 \%$ for all abnormalities and $\mathbf{9 7 . 3 \%}$ for moderate dyskaryosis or worse. We believe false negatives detected by targeted full rescreening must be included when calculating the sensitivity of primary screening. We also believe inclusion of the correction factor is important, as without it a laboratory with a low sensitivity at rapid review may falsely achieve a screening sensitivity within the recommended achievable range.

The effectiveness of a quality assurance programme should result in a reduction in the proportion of false negative cervical smears in the laboratory's files. A recognised method of quality control is the review of previous negative smears from patients who present with an abnormal smear or biopsy specimen. If rapid review is successful at reducing the number of false negative smears one would expect to see a reduction in the proportion of false negatives among the reviewed slides. In this laboratory, review of previous negatives is carried out on all cases which present with a smear or biopsy specimen suggesting cervical intraepithelial neoplasia (CIN) 2, CIN 3 or carcinoma. Sixty six slides were reviewed that were screened originally in the years 1988, 1989 and 1990 and of these, 21 (32\%) were found to contain dyskaryotic cells. The laboratory instituted rapid review at the beginning of 1991. Forty five slides screened since then have been reviewed for the reasons mentioned and of these, three $(7 \%)$ were considered to be false negative. This is a significant reduction ( $p<$ $\left.0.005, \chi^{2}\right)$ in the proportion of false negative smears within this category and is evidence that the system is effective.

The PAPNET automated screening system (NSI, Suffern, New York, USA) has been proposed as a method of quality control for rescreening of smears after conventional screening and is said to detect abnormal cells in $97 \%$ of abnormal smears. ${ }^{16}$ Our laboratory, with a false negative rate of $5 \%$ and about 500 abnormal smears per year should produce 25 false negatives annually. If we were to use the PAPNET as our sole method of internal quality control, the system should detect 24 of these $(97 \% \times 25)$. By using rapid review, we should detect $21(87 \% \times 25)$. The cost of detecting these three additional false negatives would be in excess of $£ 100000$ on scanning charges and equipment rental alone. Moreover, the time required to check a smear using the PAPNET is at least double that of rapid review. As the latter was proposed as a replacement for $10 \%$ random rescreening, the extra burden placed on the laboratory is small.

\section{Recommendations}

As a result of this study and our previous experience with partial rescreening, we can make several recommendations to laboratories who are adopting or currently using a rapid review technique. Firstly, we recommend that a prescreening trial be carried out by screeners in order to measure detection rates. This is essential as (1) it allows one to determine which members of the cytology team should carry out the procedure and (2) it allows the sensitivity of the method to be determined as this is needed to estimate accurately false negative rates. In the present study, the detection rate achieved after encountering 40 abnormals differed little to that achieved after 100 so it would seem reasonable to assess performance after 40. Secondly, adequate records of each screener's output and errors (detected by rapid review, targeted rescreening and full review) should be kept so that false negative rates for screeners and the laboratory may be calculated and monitored. And finally, we would suggest that those undertaking rapid review should achieve a detection rate of around $80 \%$. With this figure as a minimum requirement, a laboratory with a primary screening false negative rate of $20 \%$ should be able to reduce this to below the $5 \%$ benchmark for reports leaving the laboratory.

1 Koss LG. The Papanicolaou test for cervical cancer detection. A triumph and a tragedy. $¥ A M A 1989 ; 261: 737$ 43.

2 Robertson JH, Woodend B. Negative cytology preceding cervical cancer: causes and prevention. $\mathcal{F}$ Clin Pathol 1993; 46:700-2.

3 Koss LG. Cervical (Pap) Smear: New directions. Cancer 1993;71(Suppl): 1406-12.

4 Van der Graaf Y, Vooijs GP, Gaillard HLJ, Go DMD. Screening errors in cervical cytology smears. Acta Cyto 1987;31:434-8.

5 Husain OAN, Butler EB, Evans DMD, MacGregor JE, Yule R. Quality control in cervical cytology. $\mathcal{F}$ Clin Pathol 1974, 27:934-5.

6 Bogdanicz W. The Pap test misses much cervical cancer through lab's errors. Wall Street Journal 1987;Nov 2:1.

7 Bedrossian CWM, Gupta PK. Cytology in the headlines. Diagn Cytopathol 1994;11:1-3.

8 Faraker CA. Partial rescreening of all negative smears: an improved method of quality assurance in laboratorie undertaking cervical screening [correction appears in Cytopathology 1993;4:193]. Cytopathology 1993;4:47-50.

9 Faraker CA. Partial rescreening (letter). Cytopathology 1995;6:59-61.

10 Baker A, Melcher D, Smith R. Role of re-screening of cervical smears in internal quality control. $\mathcal{F}$ Clin Pathol 1995;48:1002-4

11 Dudding N. Rapid rescreening of cervical smears; an improved method of quality control. Cytopathology 1995 6:95-9.

12 HMSO. Report of the Working Party on internal quality control for cervical cytopathology laboratories. Edinburgh: The Scottish Office, 1995.

13 Achievable standards, benchmarks for reporting, criteria for evaluating cervical cytopathology. Report of a working party set up by the Royal College of Pathologists, the British Society for Clinical Cytology and the NHS Cervical Screening Programme. Cytopathology 1995;6(Suppl 2):132.

14 Koss LG. Reducing the error rate in Papanicolaou smears. The Female Patient. 1994;19(6).

15 Slater D. Cervical cytology internal quality assurancewhat are the national standards? Cytopathology 1994 5:207-10.

16 Koss LG, Lin E, Schreiber K, Elgert P, Mango L. Evaluation of the PAPNET cytologic screening system for quality control of cervical smears. Am $\mathcal{F}$ Clin Pathol 1994 101:220-9. 